\title{
Evaluation Process at the Austrian Academy of Sciences
}




\section{EVALUATION PROCESS AT THE AUSTRIAN ACADEMY OF SCIENCES}

It is the task of the Austrian Academy of Sciences to promote academic science in all fields from every perspective, particularly in terms of pure research. Accordingly, the Academy lays claim to commensurate sponsorship from public funds. It is the first research institution in Austria to establish a mechanism for permanent quality assurance through the regular publication of its Medium-Term research Programme, which forms the basis for continuation, re-orientation or conclusion of the various research institutions. The evaluation process is intended to serve programmatic orientation of the Academy and, at the same time, to ensure academic excellence on a sustained basis.

In the period 1995 to 2001, the Austrian Academy of Sciences has commissioned a systematic evaluation of all its research institutions by external experts in the relevant specialist subject areas. In the frame of its current Medium-Term Research Programme, the Academy initiated a second run of evaluation of its research institutions starting with the year 2002. Thus the Academy is reaffirming its ambition to achieve outstanding quality in its research activities, at the same time issuing an invitation to critical and attendant observation.

The current Medium-Term Research Programme Is intended to lead to the adjustment and amendment of the Academy's research aims in terms of both content and structure, and to present an opening for discussion on the following:

- The future content of research activities;

- The structure of individual areas of research; and

- Rigorous implementation of specific recommendations.

Based on its positive experience, of the Austrian the Academy will retain the format of an external evaluation by independent experts as a central element of quality assurance. Furthermore the Austrian Court of Auditors acknowledges explicitly, in its report of the examination of the Austrian Academy published in the year 2004, the achievement of the Austrian Academy of Sciences by implementing an Evaluation process of its research institutions. However the Court of Auditors identified opportunities of improvement.

In order to meet the recommendations of the Court of Auditors and to improve the ongoing Evaluation process at the Austrian Academy of Sciences, the Presiding Committee of the Academy decided in January 2005 to establish an internal working group, with the mission, to report on necessary adjustments and amendments of the administrative procedure of the Evaluation process at the Academy.

The report this working group and the decisions of the Presiding Committee there from concentrated on the following main topics:

- Strategy process

- Medium-term research Programme

- Implementation in the decision making structure

- Increasing of Transparency

- Course of Evaluation process 
The role of the Evaluation process as an external, highly qualified and future oriented initiative for the Medium-term research Programme of the Austrian Academy of Sciences has been strengthened of the past years. The Academy asks esteemed, international, scientific Institutions to propose selected, foreign researchers of the appropriate academic standing who are willing to assume responsibility for and take the initiative with regard to the formation and leadership of an external, international Evaluation Committee of experts for a particular field of research. With respect to the Autonomy of the Austrian Academy of Sciences, the Presiding Committee selects one person out of this proposed pool of specialist as head of an Evaluation Committee. The head of an Evaluation Committee, selects the further members of the Committee, as in the past, without any influence of the Academy.

The Evaluation Committee is asked to elaborate proposals for the Academy in terms of desirable avenues of research and options for implementation. In the context of this process, the Committee takes account of any changes of emphasis in the Academy's research which may impact upon such proposals, including any new institutions, restructuring, or facility closures.

The role of the Evaluation Committee is to submit proposals on its own initiative and determine the current status of a particular area of research, whereby consideration must be given to existing circumstances (research topics, identity of researchers, sponsors organizations, forms of research organization, time and resource horizons, opportunities and threats). Further, the Committee is expected to elucidate topical and academically pertinent options, describe trends, and set out new research approaches. Options for implementation must also be recorded in writing in summary, condensed form, and in terms comprehensible to academics from other disciplines.

The Evaluation Committee uses all requisite internal and external sources of information (such as, for instance, Academy fellows and Presiding Committee members, staff of the Academy's research and administrative institutions, institute advisory boards, and internal Academy documentation such as annual reports and accounts).

Following a provisional Evaluation Committee appraisal, the Presiding Committee convenes an internal discussion and invites the heads of the relevant research institutions and the competent supervisory bodies to respond. At the level of the relevant specialist subject areas, the Evaluation Committee takes account of the outcome of this discussion process in preparing their proposals and making recommendations to the Academy. This may lead to modifications in the various subject-specific provisional appraisals prepared by the Evaluation Committee.

Several associated research institutions are combined to form a field of research, which is evaluated by the Evaluation Committee. The necessary heterogeneity of the Evaluation Committee in terms of subject expertise ensures assessment from a broader disciplinary perspective. In any event, the Academy's large number of research institutions would not permit a separate evaluation of each individual institution.

The Academy's various fields of research have been and will be studied in terms of their medium-term research planning according to the following areas of research:

In the period 2003 to 2005 :

- Austria, the Danube Region and Europe

- Social Sciences

- Solid-State Physics, Biophysics and Earth Sciences

- Asian Research and Social Anthropology 
In the year 2002:

- Particle Physics and Mathematics

- Information Sciences

- European History to 1500

In the period 2006 and beyond

- Limnology, Behavioural Research and the Environment

- European Languages and Literatures

- Space Research, Astronomy and Atmospheric Physics

- Historical Sciences of Antiquity

- Prehistory and Palaeontology

- Biology and Medicine 


\begin{tabular}{|c|c|c|}
\hline Title & \multicolumn{2}{|c|}{ Austria, the Danube Region and Europe } \\
\hline Authors & \multicolumn{2}{|c|}{$\begin{array}{l}\text { Prof. Dr. Eberhard KNOBLOCH (Leitung) } \\
\text { Institut für Philosophie, Wissenschaftstheorie, Wissenschafts- und } \\
\text { Technikgeschichte, Technische Universität Berlin } \\
\text { Prof. Dr. Horst BREDEKAMP } \\
\text { Kunstgeschichtliches Seminar, Humboldt-Universität zu Berlin } \\
\text { Prof. Dr. Hermann DANUSER } \\
\text { Musikwissenschaftliches Seminar, Humboldt-Universität zu Berlin } \\
\text { Prof. Dr. Erika FISCHER-LICHTE } \\
\text { Institut für Theaterwissenschaften, Freie Universität Berlin } \\
\text { Prof. Dr.Dr.h.c. Peter MORAW } \\
\text { Historisches Institut, Justus-Liebig-Universität Giessen } \\
\text { Prof. Dr. Wolfgang SCHILD } \\
\text { Lehrstuhl für Strafrecht, Strafrechtsgeschichte und Rechtsphilosophie, } \\
\text { Universität Bielefeld }\end{array}$} \\
\hline Client & \multicolumn{2}{|c|}{ 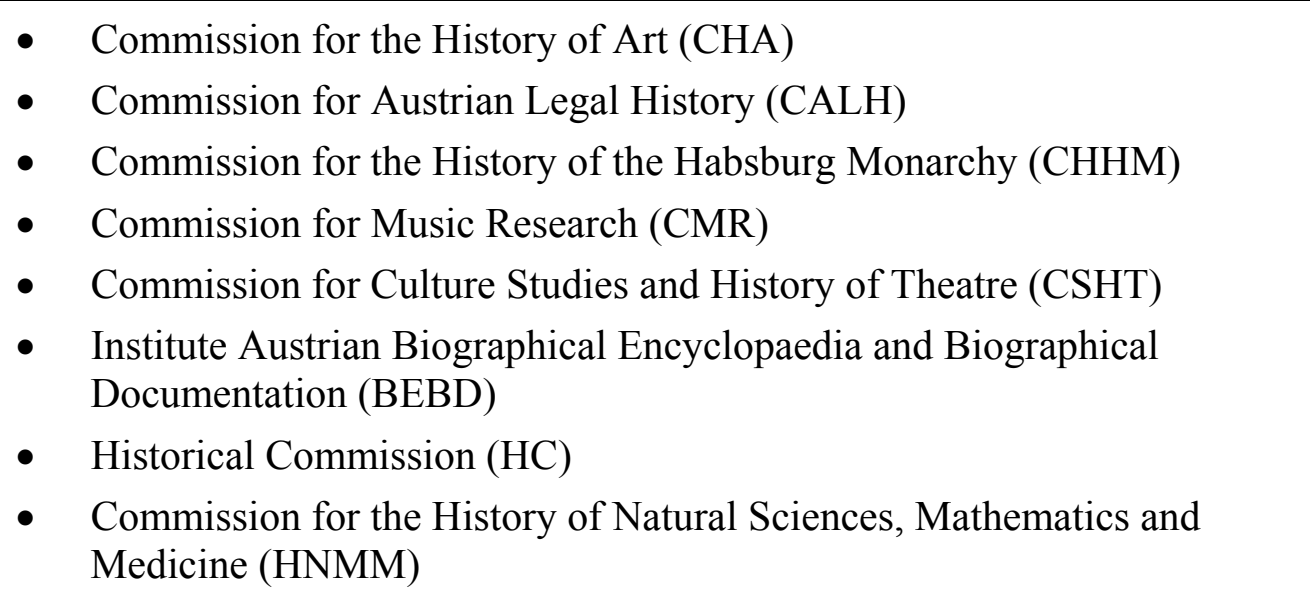 } \\
\hline Language & \multicolumn{2}{|l|}{ German } \\
\hline Date & Kick Off: & 19. 12. 2002 \\
\hline & Visit of research institutions: & 27. 05. and 29.05. - 01.06. 2003 \\
\hline & Final Report: & 05.11 .2003 \\
\hline $\begin{array}{l}\text { SUMMAR } \\
\text { Commissic } \\
\text { The main } \mathrm{p} \\
\text { the Evalua } \\
\text { cultural-his } \\
\text { humanities }\end{array}$ & $\begin{array}{l}\text { : } \\
\text { for the History of Art (CHA) } \\
\text { ject of the CHA concerning the } \\
\text { n Committee. The importance } \\
\text { ry is enormous. Furthermore it } \\
\text { ad Culture Studies. }\end{array}$ & $\begin{array}{l}\text { Viener Hofburg" is explicitly supported by } \\
\text { his research project for the Austrian art- and } \\
\text { ports the co-operation between archaeology, }\end{array}$ \\
\hline
\end{tabular}


The project "History of fine arts in Austria", a complex historical and methodological endeavour, has been finalised in a perfect manner.

The projects of the CHA are mainly subject to local Austrian questions. Therefore the international involvement is relatively low.

Recommendations:

- The framework conditions for art-history are very dynamic. Therefore it is recommended that the highly relevant research work of the CHA is amended by an accompanying discussion on methodology.

- The Austrian Academy of Sciences is very well prepared to continue its emphasis on arthistory.

\section{Commission for Austrian Legal History (CALH)}

Edition work is one of the main duties of the CALH in particular and of the Academy in general. It is a success story of the CALH. During the last few years four additional volumes of the "Fontes Juri" have been published.

Recommendations of earlier Evaluations have been implemented by the development of a bigger, coherent project beyond Austrian legal history. This project focuses on the investigation of the so called "Reichshofratsakten (ab 1519)" and is fully supported by the current Evaluation Committee as well.

Recommendations:

- In order to execute the envisaged and highly recommended projects at the CALH, one full-time co-worker and the corresponding rooms have to be provided.

\section{Commission for the History of the Habsburg Monarchy (CHHM)}

The CHHM is working on a thematic explicitly defined theme. It is recommended, that this situation is retained. The history of the Habsburg Monarchy is a big theme and of international relevance.

At the moment the whole project is designed to publish 13 volumes. The current 2 volumes are focused on "Demography" and "election-research". The status quo of the research work on these new volumes is very impressive. It reflects the extraordinary good international integration of the CHHM.

Recommendations:

- Never change a winning team. In the current situation of the whole project, it is recommended to continue the successful work by retaining the framework conditions.

\section{Commission for Music Research (CMR)}

The current head of the CMR has been installed by the Presiding Committee of the Austrian Academy of Sciences with the clear task to finalise the long-term project "Austrian music encyclopaedia". The publications of volume 1 in the year 2002 and volume 2 in march 2003 are respectable achievements. The head of the CMR succeed in one of the main issues of 
such a project, namely the grouping of the organisational und scientific energy of the coworkers. From the view point of the Evaluation Committee the publication of one volume per year till the year 2006 seems to be ambitious but realistic.

The establishment of an Online-Version of the "Austrian music encyclopaedia" is remarkable. Thus the Austrian Academy of Sciences is a cutting edge.

Recommendations:

- The lecture- and publication-work of the co-workers is remarkable. Those activities should be systematically encouraged.

\section{Commission for Culture Studies and History of Theatre (CSHT)}

The CSHT is attended to basic research in the field of the humanities. One of the basic questions is investigated with the help of theoretical approaches to memory and retrospection in the field of Culture Studies and History of Theatre. Such methodical reflections are not only remarkable research focuses in the humanities but also in the natural sciences especially in the field of brain research.

The research work of the CSHT is international state of the art. Moreover international research is influenced and partly driven by the investigations of the CSHT. The international conferences and workshop organised by the CSHT mainly aim at the integration of the CSHT and its co-workers in the international scientific community. Last but not least this approach is an optimal promotion for young researchers.

Recommendations:

- The creation of one additional full-time position at the CSHT is recommended.

- The regrouping of the room-situation at the site of the CSHT is recommended.

\section{Institute Austrian Biographical Encyclopaedia and Biographical Documentation (BEBD)}

The main task of the BEBD is the publication of the "Austrian Biographical Encyclopaedia 1815 - 1950". Furthermore one scientific co-worker is engaged in the compilation of the "Austrian Jewish Biography".

Recommendations:

- The Evaluation Committee recommends an internal restructuring of duties and responsibilities within the scientist involved in the "Austrian Biographical

Encyclopaedia 1815 - 1950”. Free capacities should be used to accelerate the finalisation of the task.

- The finalisation of the "Austrian Biographical Encyclopaedia 1815 - 1950" should have absolute priority in comparison to other research projects.

- The research work on the "Austrian Jewish Biography" seems to be fair. 


\section{Historical Commission (HC)}

The HC is the oldest Commission of the Austrian Academy of Sciences and has besides her newly formulated core-projects several duties due to her own history within the organisational structure of the Austrian Academy of Sciences. The selection of the coreprojects is justified.

The HC has the duty and the commitment like no other research institution in Austria to deal, within her own research activities and of course in general as well, with the concept of Austria and its reflection in history. This conception is relevant for the historical sciences in Austria and worldwide and in particular for the other historical research institutions at the Austrian Academy.

Recommendations:

- The Evaluation Committee recommends to make an own room available for the head of the $\mathrm{HC}$ at the current site.

\section{Commission for the History of Natural Sciences, Mathematics and Medicine (HNMM)}

The HNMM belongs latterly to the historical Commissions of the Austrian Academy of Sciences. The Evaluation Committee welcomes this organisational restructuring although the HNMM is of course still in urgent need of expertise in Mathematic, Natural Sciences and Medicine.

Besides the indexing of the collection "Erich Woldan" one of the main activities of the HNMM is work in the field of public relation, public understanding and public awareness.

\section{Recommendations:}

- The Evaluation Committee strongly recommends supporting especially the activities in the field of communicating science.

- The improvement of the situation of the collection "Erich Woldan" in terms of maintenance, accommodation and financial resources is recommended. 


\begin{tabular}{|c|c|c|}
\hline Title & \multicolumn{2}{|l|}{ Social Sciences } \\
\hline Authors & $\begin{array}{l}\text { Prof. Dr. Karl Ulrich MAYEF } \\
\text { Max-Planck-Institut für Bildu } \\
\text { Prof. Dr. Ortwin RENN } \\
\text { Institut für Sozialwissenschaf } \\
\text { Techniksoziologie, Universitä } \\
\text { Prof. Dr. Ronald LESTHAEG } \\
\text { Centrum voor Sociologie, Vri } \\
\text { Prof. Dr. Jürgen FRIEDRICH } \\
\text { Forschungsinstitut für Soziolo } \\
\text { Prof. Dr. Jürgen VON HAGE } \\
\text { Zentrum für Europäische Inte }\end{array}$ & $\begin{array}{l}\text { Leitung) } \\
\text { sforschung, Berlin } \\
\text {, Abteilung für Umwelt- und } \\
\text { Stuttgart } \\
\text { Eniversiteit Brussel } \\
\text { e, Universität zu Köln } \\
\text { tionsforschung, Bonn }\end{array}$ \\
\hline Client & \multicolumn{2}{|c|}{$\begin{array}{ll}\text { - } & \text { Institute for Technology Assessment (ITA) } \\
\text { - } & \text { Institute for Demography (IfD) } \\
\text { - } & \text { Institute for Urban and Regional Research (ISR) } \\
\text { - } & \text { Research Unit for Institutional Change and European Integration (ICEI) } \\
\text { - } & \text { Commission for Historical Press Research (CHPR) }\end{array}$} \\
\hline Language & \multicolumn{2}{|l|}{ German and partly in English } \\
\hline \multirow[t]{3}{*}{ Date } & Kick Off: & 25.11 .2002 \\
\hline & Visit of research institutions: & 16. -20.06 .2003 \\
\hline & Final Report: & 28.01 .2004 \\
\hline \multicolumn{3}{|c|}{$\begin{array}{l}\text { The co-workers at the ITA are highly motivated and qualified. The collaboration and co- } \\
\text { operation of the co-workers among each others is very good. The head of the institute } \\
\text { established a motivating atmosphere which encourages the co-workers to develop common } \\
\text { aims and targets. }\end{array}$} \\
\hline \multicolumn{3}{|c|}{$\begin{array}{l}\text { The research work in the field of "Information Society" and "Biotechnology" has gained } \\
\text { international recognition. The field of "Health Technology Assessment" is considered as } \\
\text { very sustainable. However due to the clear orientation of the ITA to policy advice, the field of } \\
\text { "Health Technology Assessment" fits not very well to the general work programme of the } \\
\text { ITA. }\end{array}$} \\
\hline \multicolumn{3}{|c|}{$\begin{array}{l}\text { - The Evaluation Committee recommends the continuation of the ITA. } \\
\text { - The Evaluation Committee recommends involving more strongly external experts in the } \\
\text { development of strategic research targets and mission statements. } \\
\text { - In order to encourage the interdisciplinary collaboration at the ITA, the Evaluation } \\
\text { Committee recommends strengthening of the strategic focus of the research work at ITA }\end{array}$} \\
\hline
\end{tabular}


in general.

- The research field "Health Technology Assessment" should be further developed.

- Evidence of concerted development of methodical Know-How is clearly visible. This exercise should be intensified in the future.

\section{Institute for Demography (IfD)}

Demography is a multifaceted science which flourishes best in a multidisciplinary environment. The implementation at an institute of the Austrian Academy of Sciences is the best guarantee for such multidisciplinary. A critical mass of researchers and this can best be brought together at a national level, and in an academic rather than I a political or administrative environment.

\section{Recommendations:}

- The continuation of the IfD is strongly recommended. And the same holds for the current internationalisation policy for as long as this does not weaken the national significance of the Institute.

- The IfD should become a place for cross-fertilization of micro- and macro-approaches. A too exclusive orientation to macro-demographic issues, particularly when coupled to "mechanistic" approaches, is to be avoided. In other words, the IfD should build a reputation for its balanced multi-paradigmatic approach in the social sciences.

- If the Austrian Academy would create new research activities on Migration and Minority population, then the IfD should play a major role in it.

- Stronger co-operation with other Austrian institutions is needed since the IfD cannot afford to retreat to narrow formal demographic interests. The IfD should develop research initiatives with Austrian research groups working on migration and integration and in the domains of social security research and macro-economic planning issues.

\section{Institute for Urban and Regional Research (ISR)}

The research programme of the ISR consists of three main fields: "Urban Research", "Spatial Social Research" and "Regional Research". The director of the ISR succeeded in giving the Institute a new profile in amazingly short time, mainly with the help of very successful applications for third party funds. Furthermore he attracted a great number of young and highly qualified co-workers with different scientific background to do their research work at the ISR.

\section{Recommendations:}

- Subsequent to the fast and successful reorientation of the ISRT it is recommended to start a phase of consolidation. This could happen by retaining the fraction of third party funds in comparison to the ordinary budget and by using the newly developed networks for stronger common publication activities and specific small projects.

- A focusing on basic research in general is recommended. Furthermore a stronger focus should be laid on theory-driven research work.

- The Austrian Academy should examine how migration research could be co-ordinated and strengthened in Austria in general. In the field of "Spatial Social Research" migration 
research should be established at the ISR.

\section{Research Unit for Institutional Change and European Integration (ICEI)}

The ICEI investigates processes of institutional change in Europe including its forecast and its consequence with a main focus on the changes in connection with European integration and the development of the European information society.

The ICEI has gained without any doubt broad attention during the last years in the Austrian public discussion. This shows up last but not least in the interest of political and economic institutions in the work of the ICEI.

Recommendations:

- The ICEI should concentrate its future research work on the connection between jurisprudence and political sciences. Furthermore the ICEI should follow an empirical approach.

- The research work in the field of European information society has no visible potential for further development.

- The Evaluation Committee recommends the possibility for the research group on "European Migration- and Integration" to develop a research programme over a temporary period.

- The Evaluation Committee recommends developing a strategy concerning publications and an increasing of publications in international highly prestigious journals.

- The Evaluation Committee recommends a stronger involvement of foreign guest researchers.

\section{Commission for Historical Press Research (CHPR)}

The CHPR has developed in a worldwide unique manner from an archiving- and documentation-project to an innovative research institution for the investigation of the longterm changes of the Austrian daily newspaper market and the analysis of the presentation of policy with an emphasis on election communication in the media.

The CHPR succeeds to connect in extraordinary manner historical, socio-scientific and cultural-scientific Theories and research approaches.

The work of the CHPR is of international relevance and its achievements are utilized accordingly.

The promotion of young researchers, which is financed mainly via third-party-funds, is appraised as very positive.

Recommendations:

- It is recommended to develop a working programme for the next years with a special emphasis on the relation between documentation- und research-work.

- The external usage of the compiled data of the CHPR should be intensified by additional resources for guest-researchers or young scientists.

- The scientific output of the co-workers is with the given limited resources extraordinary good. An increase of the human resources and therewith a distribution of the duties is 
recommended.

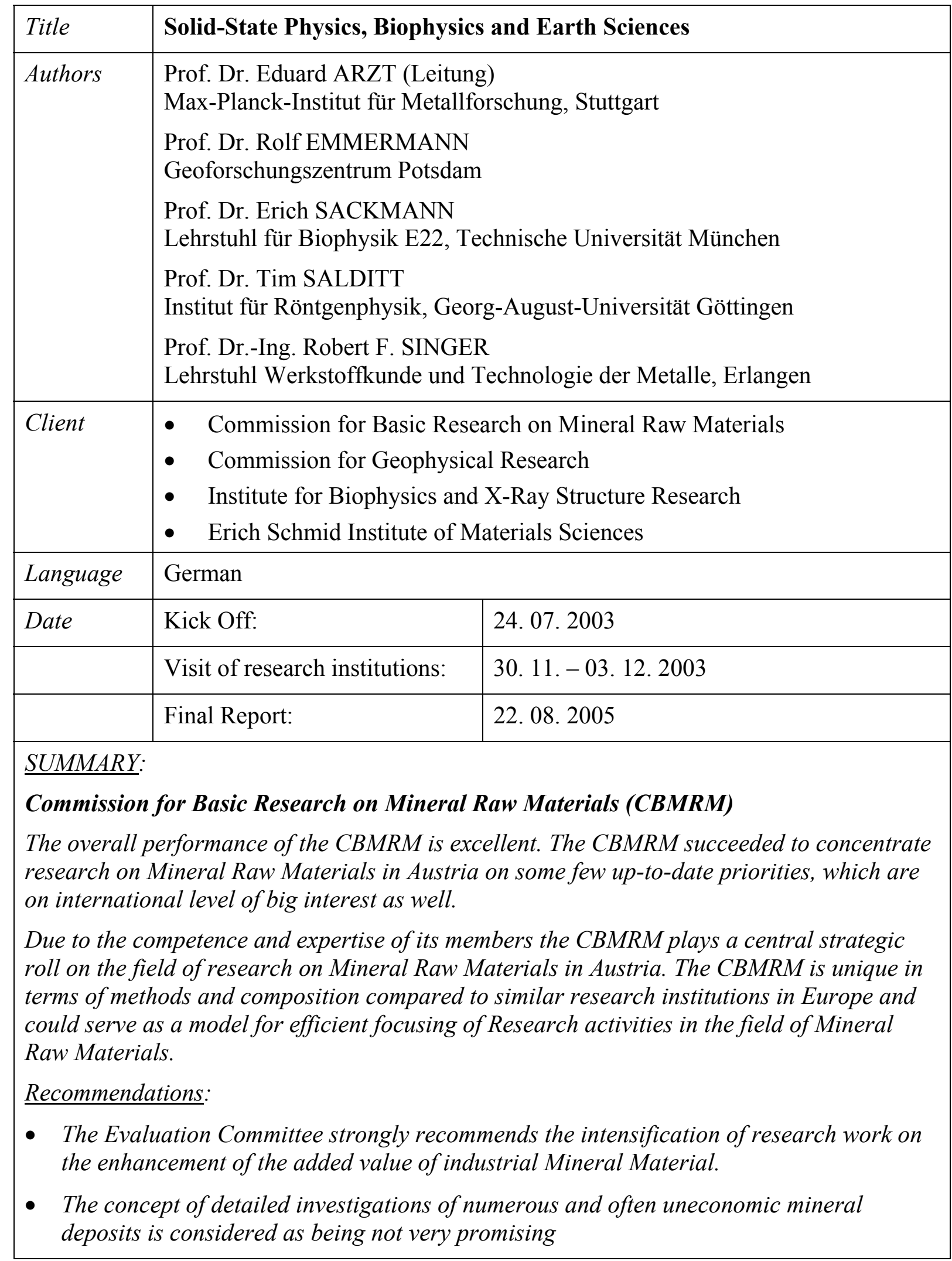


- In order to support the outstanding position of Austria in the field of Mineral Raw Materials the CBMRM should enforce its endeavours on the promotion of young researchers.

\section{Commission for Geophysical Research (CGR)}

All three research fields of the CGR, glaciology, gravimetry and reflection-seismic are of high scientific interest and are handled very competent and successfully. With respect to the global climate change the project on glaciology is of special international importance.

\section{Recommendations:}

- The quantitative acquisition of dynamic changes of glaciers is an important long term exercise, which can only be dealt with in the frame of an institution like the Austrian Academy of Sciences. In order to strengthen the outstanding Austrian position in the field of glaciology the co-operation with other research fields like climatology and geography should be intensified.

- Therefore the CGR should aim at increasing its national and international visibility.

- The planned establishment of the new thematic focus "Socio-economic relevance of alpine glaciers for water management, tourism and agriculture" does not fit in the overall concept of the CGR.

- The thematic focus on gravimetry should be finalised within the next two years.

- The continuation of the thematic focus on reflection-seismic should be reconsidered.

\section{Institute for Biophysics and X-Ray Structure Research (IBR)}

The overall performance of the scientific work at the IBR is very good; in some fields it is excellent. Quantity, quality and impact of the publications are very good. In some fields the IBR has generated outstanding results and therefore obtained worldwide publicity.

The scientific qualification and the engagement of the co-workers of the IBR, and especially the young scientists are impressing. This situation is reflecting an excellent guidance and motivation by the head of the institute. The extraordinary promotion of female scientists is worth mentioning.

Recommendations:

- In order to enhance the future opportunities especially of the young scientists the relations to the physical and physical-chemical departments at the Universities in Graz should be intensified.

- The research fields at the IBR are quite close to biological application. Therefore an extension of genetically work seems to be important.

- The international integration of the IBR is extraordinary good. Nevertheless, the embedding in the national scientific community seems to be low. The Evaluation Committee recommends starting endeavours to increase the perception of the IBR and therewith the perception of Biophysics in Austria. 


\section{Erich Schmid Institute of Materials Sciences (ESI)}

The overall performance of the scientific work at the ESI is very good; in some fields it is excellent. The extension of the research fields during the last years to biological materials increased the international perception of the ESI dramatically. Meanwhile the ESI plays on international level a lead role in this field.

The relation to the Universities especially in Leoben seems to be good. The close connection to the Institute of Metal Physics effects very positive synergy effects for both sides the Austrian Academy of Sciences and the University of Leoben.

A comparable high number of qualified young researchers are working at the ESI. The ESI is attractive for young researchers from abroad especially from the central and eastern European countries. The occupational outlook of alumni especially in the industry is very good.

\section{Recommendations:}

- The activities in the field of simulation and modelling should be intensified.

- In general the scientific investigation and the focusing on special fields are more important than the completeness of the group of materials concerned.

- The good relation to the University of Leoben should be extended. A strategic cooperation with the Institute of Metal Physics under the lead of a dedicated director will have positive effects for the institutions involved as well as for the research location Leoben. 


\begin{tabular}{|c|c|c|}
\hline Title & \multicolumn{2}{|c|}{ Asian Research and Social Anthropology } \\
\hline Authors & \multicolumn{2}{|c|}{$\begin{array}{l}\text { Prof. Dr. Peter ZIEME (Leitung) } \\
\text { Akademievorhaben Turfanforschung, Berlin-Brandenburgische Akademie der } \\
\text { Wissenschaften } \\
\text { Prof. Dr. Antonio PANAINO } \\
\text { Dipartimento di Storie e Metodi per la Conservazione dei Beni Culturali, } \\
\text { Università di Ravenna } \\
\text { Prof. Dr. Georg PFEFFER } \\
\text { Institut für Ethnologie, Freie Universität Berlin } \\
\text { Prof. Dr. Erling VON MENDE } \\
\text { Ostasiatisches Seminar Sinologie, Freie Universität Berlin }\end{array}$} \\
\hline Client & \multicolumn{2}{|c|}{$\begin{array}{ll}\text { - } & \text { Institute for the Cultural and Intellectual History of Asia (ICIHA) } \\
\text { - } & \text { Commission for Social Anthropology (CSA) } \\
\text { - } & \text { Institute for Iranian Studies (IIS) }\end{array}$} \\
\hline Language & \multicolumn{2}{|l|}{ German } \\
\hline \multirow[t]{3}{*}{ Date } & Kick Off: & 09.01 .2004 \\
\hline & Visit of research institutions: & 07. - 09.06. 2004 \\
\hline & Final Report: & 02.03 .2005 \\
\hline \multicolumn{3}{|c|}{$\begin{array}{l}\text { In general the ICIHA succeeded to concentrate on excellent basic research in the field of } \\
\text { philology. The head of the institute affords to establish very good working conditions on the } \\
\text { basis of excellent supervision in form and content. The work of the Institute proves to be very } \\
\text { effective. }\end{array}$} \\
\hline \multicolumn{3}{|c|}{$\begin{array}{l}\text { The co-workers at the ICIHA are entirely well-established scientist. Besides their research } \\
\text { activities more or less all co-workers at the ICIHA are working as teachers at the University } \\
\text { as well. Therefore the integration of the ICIHA in the scientific community is visible. The } \\
\text { scientific quality of the co-workers guarantees the cross linking of the ICIHA with the } \\
\text { upcoming new generations of students. }\end{array}$} \\
\hline \multicolumn{3}{|c|}{$\begin{array}{l}\text { By the organisation and the attendance of workshops and conferences the ICIHA established } \\
\text { a intense international interchange of ideas. The co-operation with the University of Vienna } \\
\text { is ideal. }\end{array}$} \\
\hline \multicolumn{3}{|c|}{$\begin{array}{l}\text { - The Austrian Academy of Sciences should unconditionally support the ICIHA. } \\
\text { Furthermore the Evaluation Committee strongly recommends retaining the }\end{array}$} \\
\hline $\begin{array}{l}\text { budge } \\
\text { - Co-op } \\
\text { the fie }\end{array}$ & ICIHA. & 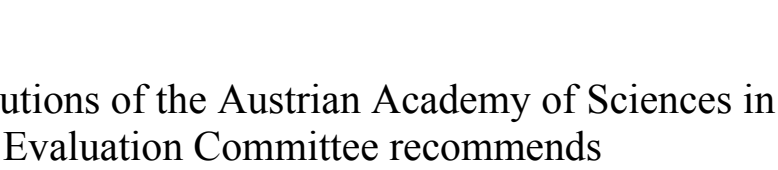 \\
\hline
\end{tabular}


intensifying and strengthening these contacts.

- The Evaluation Committee recommends the utilization of the possibilities of the internet particularly for the presentation and publication of scientific results.

\section{Commission for Social Anthropology (CSA)}

The Evaluation Committee appreciates the decision of the Austrian Academy of Sciences, to support Ethnology and Social Anthropology within the frame of a Commission of the Academy. Within the German-speaking countries this initiative is comparable only with the MPI for ethnological research in Halle.

The research activities at the CSA are of high quality. Due to the endeavours of its head, the CSA is an active and noticeable Commission. Furthermore the CSA is very well connected on an international level.

\section{$\underline{\text { Recommendations: }}$}

- The Evaluation Committee recommends the continuation of the CSA beyond the year 2006. The Austrian Academy of Sciences is challenged to take all necessary steps to cover the connected additional expenditure in comparison to the status quo.

- The Evaluation Committee does not see the necessity to sum up the different projects within two major research topics. The Evaluation Committee appreciates explicitly the extraordinary research work done in Arabia, South-East Asia, the Himalaya region and Venezuela; a continuation and a deepening is strongly recommended.

\section{Institute for Iranian Studies (IIS)}

The encouragement of the field of Iranian Studies at the Austrian Academy of Sciences by the constitution of an Institute for Iranian Studies is an outstanding enrichment of the Austrian scientific landscape.

The head of the IIS owns, besides his exceptional scientific expertise, the personal competence to form an efficient and convincing research group. The publications of the coworkers of the IIS are distinguished and scientifically important. The international reputation of the co-workers of the IIS is high.

The international visibility of the IIS is very high. Furthermore the co-operation with institutions of the Austrian Academy, other Austrian research institutions and international partners is very good. Unfortunately the instantaneous connection to the universities is missing due to the fact that the Iranian Studies do not exist as subject at Austrian universities.

\section{Recommendations:}

- Within a very short period of time the IIS succeeded in establishing an impressive library buy way of purchase and donation. It is an attraction for Austrian and international colleagues and contributes to the reputation of the Austrian Academy of Sciences. The Evaluation Committee recommends retaining the personnel and financial resources for the library of the IIS at least over the next three years.

- The Evaluation Committee explicitly appreciates the planned initiative of the IIS called "Central European Network of Iranian Studies". This convincing idea will strengthen the international roll of the IIS and will enable especially countries like Poland, Hungary, 
Czech Republic, Germany and Italy to participate.

Further more the following fields of research have been evaluated in the year 2002:

\begin{tabular}{|c|c|c|}
\hline Title & \multicolumn{2}{|c|}{ Particle Physics and Mathematics } \\
\hline Authors & \multicolumn{2}{|c|}{$\begin{array}{l}\text { Prof. Dr. Klaus PINKAU (Leitung) } \\
\text { Max-Planck-Institut für Plasmaphysik, München } \\
\text { Prof. Dr. Willi JÄGER } \\
\text { Interdisziplinäres Zentrum für Wissenschaftliches Rechnen, Universität } \\
\text { Heidelberg } \\
\text { Prof. Dr. Paul KIENLE } \\
\text { Physik-Department E12, Technische Universität München } \\
\text { Prof. Dr. Robert KLANNER } \\
\text { DESY Hamburg }\end{array}$} \\
\hline Client & \multicolumn{2}{|c|}{$\begin{array}{ll}\text { - } & \text { Institute for High Energy Physics } \\
\text { - } & \text { Institute for Medium Energy Physics } \\
\text { - } & \text { Institute of Discrete Mathematics } \\
\end{array}$} \\
\hline Language & \multicolumn{2}{|l|}{ German } \\
\hline Date & Kick Off: & 26.10 .2001 \\
\hline & Visit of research institutions: & 04. - 08.02. 2002 \\
\hline & Final Report: & 22.03 .2002 \\
\hline
\end{tabular}

\begin{tabular}{|c|c|}
\hline Title & Information Sciences \\
\hline Authors & $\begin{array}{l}\text { Prof. Dr. Grzegorz DOGIL (Leitung) } \\
\text { Institut für Maschinelle Sprachverarbeitung und Experimentelle Phonetik, } \\
\text { Universität Stuttgart } \\
\text { Prof. Dr. Elisabeth ANDRÉ } \\
\text { Lehrstuhl für Informatik und Multimedia Konzepte und Anwendungen, } \\
\text { Universität Augsburg } \\
\text { Prof. Dr. Hermann ACKERMANN } \\
\text { Neurologische Klinik der Universität Tübingen } \\
\text { Prof. Dr. Werner KALLMEYER } \\
\text { Institut für Deutsche Sprache, Mannheim }\end{array}$ \\
\hline Client & $\begin{array}{l}\text { - } \text { Commission for Linguistics and Communication Research } \\
\text { - } \text { Phonogram Archive } \\
\text { - } \text { Acoustics Research Institute } \\
\text { - } \quad \text { Commission for Scientific Visualization }\end{array}$ \\
\hline Language & German \\
\hline
\end{tabular}




\begin{tabular}{|l|l|l|}
\hline Date & Kick Off: & 11.01 .2002 \\
\hline & Visit of research institutions: & $09 .-12.04 .2002$ \\
\hline & Final Report: & 30.12 .2002 \\
\hline
\end{tabular}

\begin{tabular}{|c|c|c|}
\hline Title & \multicolumn{2}{|l|}{ European History to 1500} \\
\hline Authors & \multicolumn{2}{|c|}{$\begin{array}{l}\text { Prof. Dr. Marie Theres FÖGEN (Leitung) } \\
\text { Lehrstuhl für Römisches Recht, Privatrecht und Rechtsvergleich, Universität } \\
\text { Zürich } \\
\text { Prof. Dr. Rosamond McKITTERICK } \\
\text { Faculty of History University of Cambridge } \\
\text { Prof. Dr. Otto Gerhard OEXLE } \\
\text { Max Planck-Institut für Geschichte, Göttingen } \\
\text { Prof. Dr. Diether Roderich REINSCH } \\
\text { Byzantinisch-neugriechisches Seminar, Freie Universität Berlin } \\
\text { Prof. Dr. Bernard H. STOLTE } \\
\text { Faculteit der rechtsgeleerdheit, Rijksuniversiteit Groningen }\end{array}$} \\
\hline Client & \multicolumn{2}{|c|}{$\begin{array}{l}\text { - } \text { Commission for Byzantine Studies } \\
\text { - } \quad \text { Commission for the Tabula Imperii Byzantini } \\
\text { - } \quad \text { Institute for Research into the Daily Life and Material Culture of the } \\
\text { Middle Ages and the Early Modern Period } \\
\text { - Medieval History Research Unit } \\
\text { - Commission for Palaeography and Codicology of Medieval Manuscripts } \\
\text { in Austria }\end{array}$} \\
\hline Language & \multicolumn{2}{|l|}{ German } \\
\hline \multirow[t]{3}{*}{ Date } & Kick Off: & 28.02. 2002 \\
\hline & Visit of research institutions: & $21 .-25.06 .2002$ \\
\hline & Final Report: & 07.10 .2002 \\
\hline
\end{tabular}

\section{Author}

Bernhard Plunger

Verwaltungsstelle für Auslandsbeziehungen

Postgasse 7-9, 1010 Wien

bernhard.plunger@oeaw.ac.at

Mag. Bernhard Plunger studied physics at the University of Innsbruck. He is head of the foreign relations department of the Austrian Academy of Sciences. Since 2001 Bernhard Plunger is responsible for the administrative coordination of the Evaluation procedure of the research institutions of the Austrian Academy of Sciences. 